\title{
Erratum to: Pediatric Nephrology, Volume 29, Issue 5 (2014)
}

\author{
Marcia Rejane Thomas Canabarro Andrade • \\ Lívia Azeredo Alves Antunes • \\ Rosangela Maria de Araújo Soares • \\ Anna Theresa Tome Leão • Luciane Cople Maia • \\ Laura Guimarães Primo
}

Published online: 23 May 2014

(C) IPNA 2014

\section{Erratum to: Pediatr Nephrol \\ DOI:10.1007/s00467-013-2437-4 \\ DOI:10.1007/s00467-013-2436-5}

Erratum to: Lower dental caries prevalence associated to chronic kidney disease: a systematic review

$$
\text { 10.1007/s00467-013-2437-4 }
$$

Erratum to: Chronic kidney disease: a new look at pathogenetic mechanisms and treatment options

10.1007/s00467-013-2436-5

These articles were paginated incorrectly in Vol. 29, No. 5: the correct page numbers for article 467-2437 are 771-778 and for the article 467-2436, 779-792.

The publisher apologizes for any inconvenience caused.

The online version of the original article can be found at http://dx.doi.org/ $10.1007 / \mathrm{s} 00467-013-2437-4$ and 10.1007/s00467-013-2436-5.

M. R. T. C. Andrade • L. C. Maia • L. G. Primo $(\bowtie)$

Department of Pediatric Dentistry and Orthodontics,

School of Dentistry, Federal University of Rio de Janeiro,

Rio de Janeiro, RJ, Brazil

e-mail: 1primo@pobox.com

\section{A. A. Antunes}

Department of Specific Formation, School of Dentistry,

Fluminense Federal University, Nova Friburgo, Brazil

R. M. d. A. Soares

Department of General Microbiology,

Federal University of Rio de Janeiro, Rio de Janeiro,

RJ, Brazil

\section{A. T. T. Leão}

Department of Dental Clinic, Division of Graduate Periodontics,

School of Dentistry, Federal University of Rio de Janeiro,

Rio de Janeiro, RJ, Brazil

\section{R. T. C. Andrade}

Disciplina de Odontopediatria da FO-UFRJ, Cidade

Universitária - Centro de Ciências da Saúde (CCS),

Caixa Postal 68066, Rio de Janeiro 21941-971, Brazil 